\title{
Survey and Analysis of the Sediment Transport for River Restoration: The Case of the Mangyeong River
}

\author{
Joongu Kang, Hongkoo Yeo \\ Water Resource Research Department, Korea Institute of Construction Technology, Goyang, Republic of Korea \\ Email: jgkang02@kict.re.kr
}

Received 14 July 2015; accepted 8 December 2015; published 11 December 2015

Copyright (C) 2015 by authors and Scientific Research Publishing Inc.

This work is licensed under the Creative Commons Attribution International License (CC BY). http://creativecommons.org/licenses/by/4.0/

c) (i) Open Access

\begin{abstract}
In a river, sediment discharge, which goes through erosion, transport, and deposition by flowing water, is important data for river projects. The transport of river sediment occurs depending on the conveyance of a channel as the basin sediment discharge, which has been introduced to the river via the outflow of the basin by the erosion of fertile topsoil or ground surface due to rainfall in the target basin, and the sediment eroded within the channel is mixed together. River sediment is a major factor for river formation and ecological habitat, and is a field that is difficult to analyze or predict. For the abandoned channel restoration of the Mangyeong River, this study aimed to develop a discharge-suspended sediment load rating curve by collecting suspended load and bed material at the Bong-dong gauging station, which is a test section. The developed discharge-suspended sediment load rating curve was proposed based on the existing discharge data and the measured sediment load. The measured data and the rating curve will be used as the major data for stability and habitat restoration during channel restoration.
\end{abstract}

\section{Keywords}

Sediment Load, Discharge-Sediment Load Rating Curve, Restored Channel

\section{Introduction}

Sediment discharge, which passes a certain spot of a river through erosion, transport, and deposition by flowing water, is valuable data for establishing a comprehensive basin flood control plan, along with discharge, stage, and rainfall. The transport of river sediment occurs depending on the conveyance of a channel as the basin sediment discharge, which has been introduced to the river via the outflow of the basin by the erosion of fertile 
topsoil or ground surface due to rainfall in the target basin, and the sediment eroded within the channel is mixed together.

A river plays a role in transporting sediment that occurs within the basin or channel (i.e., 3-stage processes of erosion, transport, and deposition) as well as conveying the outflow due to rainfall. Erosion decreases the yield of farmland by carrying away the fertile soil of a basin, destroys river banks or river structures by eroding the river beds, and threatens the lives and properties of the public by damaging bridges, tidal outlets, weirs, fishways, or navigation facilities. Transport, which occurs by the inflow of the sediment due to the sediment discharge of a basin into the river channel, damages floodplains that are used for multiple purposes, and causes many sediment damages as banks are flooded and deposition occurs in farmland, residential area, road facilities, and various facilities. Locally, it abrades hydraulic machinery (e.g., turbines or pumps) that is operated for the purpose of the discharge for power generation, and also causes extensive damages to fish farms, water, navigation, and water treatment.

Resolving various sediment problems that occur in the above processes is recognized as one of the most difficult problems that hydraulic engineers face. If sediment is introduced to a channel and a reservoir during flood, the sediment is deposited in the channel due to the topographic and hydraulic characteristics of the channel, and thus, the cross sectional area of flow for the river decreases, and the scale of flood and inundation increases. Also, it plays a critical role in interrupting the water management and flood control functions of the reservoir by decreasing the reservoir capacity. To minimize the damage from sediment, appropriate sediment control plan and comprehensive basin flood control plan need to be established based on sediment load measurement data. Also, the safety and utility of structures need to be maximized by predicting a potential stable bed using a bed change model that is appropriate for the channel characteristics and by applying this to the design of hydraulic structures such as bridges, drains, or culverts. As basin development increases, the significance of basin management becomes more important. Therefore, for this purpose, research and effort for securing diverse and accurate sediment load measurement data are required.

For the abandoned channel restoration of the Mangyeong River, this study aimed to develop a dischargesuspended sediment load rating curve by collecting suspended load and bed material at the Bong-dong gauging station, which is a test section. The sediment load data will be used as the major data for stability and habitat restoration during channel restoration. Therefore, this study aimed to prepare basic data for river restoration by recognizing the importance of a sediment load measurement method and data processing procedure and by systematizing an analysis method from survey to processing.

\section{Target Area}

The Mangyeong River is a river that originates from Mt. Wondeung in Dongsang-myeon, Wanju-gun, Jeollabuk-do; meets the tributaries such as the Gosan Stream, the Soyang Stream, and the Jeonju Stream; and flows into the Yellow Sea. It has a basin area of $1527.1 \mathrm{~km}^{2}$, and a river length of $77.4 \mathrm{~km}$. The bed slopes of the Mangyeong River are 1/3,800 at the $30 \mathrm{~km}$ downstream section of the Mangyeong River, 1/540 up to the $50 \mathrm{~km}$ midstream section, and 1/120 at the upstream section. For the Soyang Stream and the Jeonju Stream, the bed slopes are about $1 / 360$ and $1 / 700$, respectively. Thus, in most sections excluding the downstream section of the main stream of the Mangyeong River, the slopes are relatively steep. The bed of the main stream of the Mangyeong River at the downstream section of the confluence with the Jeonju Stream consists of silt and clay; and the beds the upstream section and the Soyang Stream/the Jeonju Stream consist of sand and gravel. Most flood plane in riverside land is used as farmland. The shape of the basin is close to dendritic (Figure 1, MOCT [1]).

\section{Sediment Load Measurement and Analysis}

The behaviour of sediment is active when the outflow of a basin due to rainfall is dominant. Accordingly, by classifying this situation as a flood season, 15 sediment measurements were planned, respectively, and the sediment load measurement results were secured by collecting the sediment of the flood season for 19 times. The measurements were made only in the flood season, and the flood season was focused on July-August, when the movement of sediment is active. To estimate total sediment load by examining the behaviour of bed sediment load, the collection of bed material also needs to be performed during the sediment load measurement. However, due to the lack of the equipment for performing this and the space for equipment installation in the field, bed 


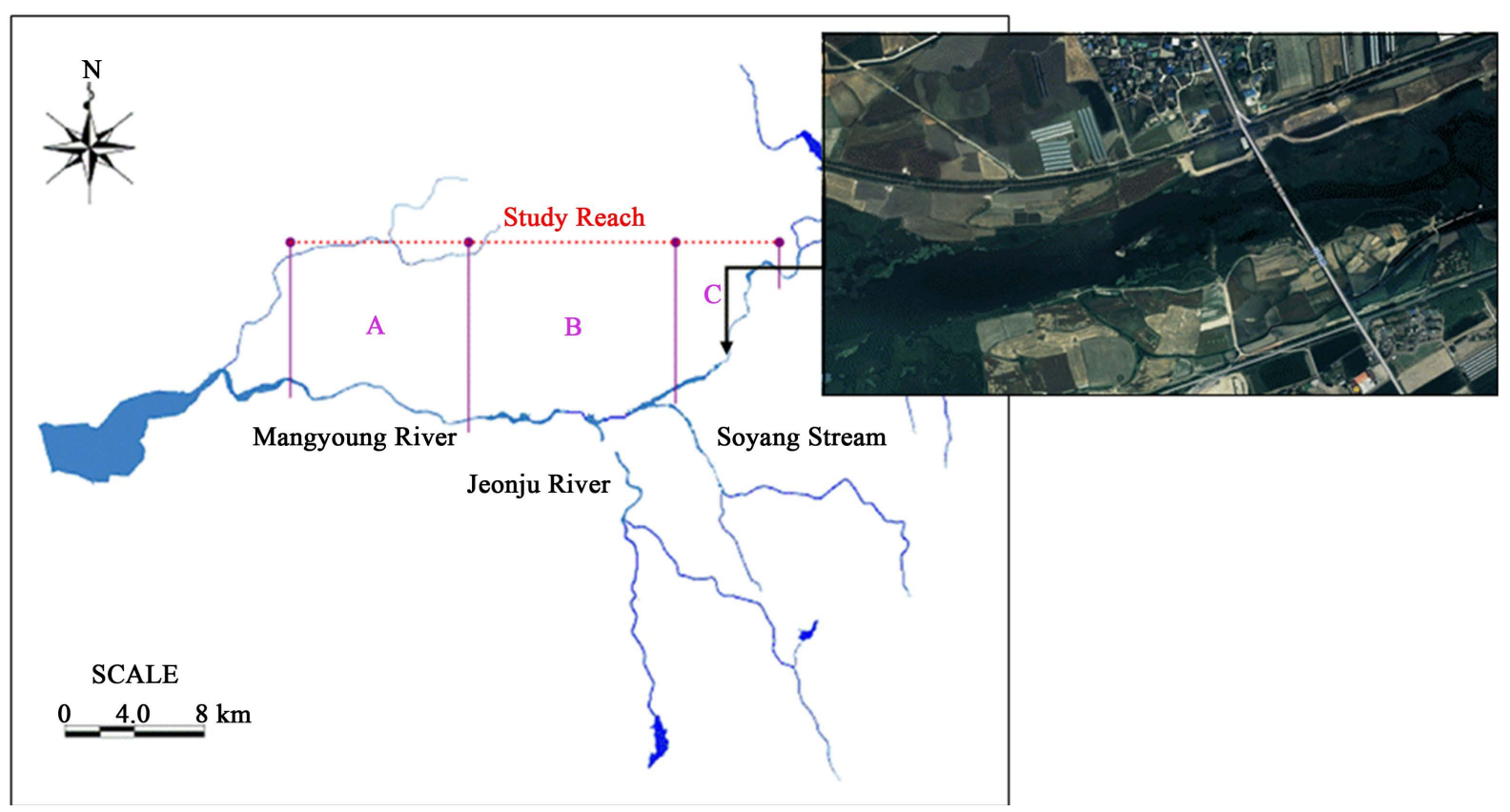

Figure 1. Locations for the sediment load measurement.

material was collected once before the flood season. Also, as there was no auxiliary staff gauge for measuring water surface slope, the equilibrium bed slope of the Yongbong Bridge (MOCT [1]) was used.

For the sediment load measuring device, appropriate device type needs to be selected considering the water depth, flow velocity, and measurement condition that are suitable for the channel characteristics of the target spot. Accordingly, D-74 was used, and the maximum water depth that can be measured is about $5 \mathrm{~m}$. At the time of the measurement, the annual maximum water depth at the Bong-dong spot was about $3 \mathrm{~m}$. Thus, measurement was made using D-74 based on the return water-depth integration method. The bed material mostly consists of large gravel and boulders, and thus could not be collected using a bed material sampler. Accordingly, among grid sampling methods, which are the sample collection methods of coarse-grained bed material, a method in which samples are collected at regular intervals of a tape measure, was used. For the arrangement of the survey line, the entire cross section was divided into several partial sections. By measuring sediment at the survey line that represents the partial section, flow-weighted average sediment concentration was calculated. The Bong-dong gauging station is located at the main stream of the Mangyeong River; and in the upstream, the Gosan gauging station is located. The maximum stage for the measurement period was $3.35 \mathrm{~m}$, which was measured during the concentrated heavy rain period that occurred between July 9 and July 15. A total of 19 measurement results were secured by collecting a lot of sediment ranging from the maximum stage that occurred during this period to the stage rise and fall. To examine the status of the discharge and sediment load measurement results that had been measured during the flood season at the gauging station, they were plotted on a stage-hydrograph along with the rainfall condition, as shown in Figure 2. The discharge-sediment load relation could be appropriately investigated when discharge and sediment load are measured at the same time during sediment load measurement. Therefore, hydraulic data necessary for the analysis of sediment load were calculated using the stage-discharge rating curve developed in the 2008 Discharge Survey Report (HSC [2]), as summarized in Table 1.

\section{Sample Analysis}

Different methods for analyzing suspended load concentration can be used depending on the suspended load concentration characteristics of samples. It is generally known that when suspended load concentration is high, the evaporation method is more efficient than the filtration method; and in the case of low concentration, the filtration method is appropriate. In this study, the suspended load concentrations were analyzed using the filtration method. Suspended sediment load is generally defined as the product of average concentration and discharge, 


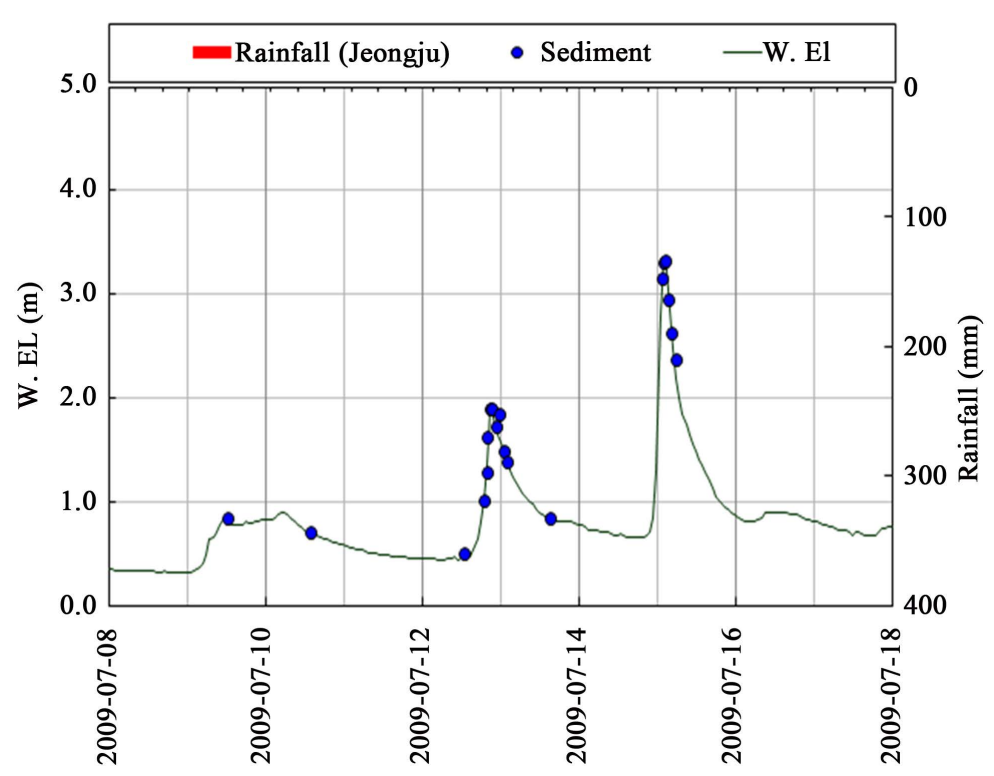

Figure 2. Comparison of the gauge stage and sediment load measurement results (flood season).

Table 1. Stage-discharge rating curve (2008).

\begin{tabular}{|c|c|c|c|c|c|}
\hline Spot & Stage (m) & Stage-discharge rating curve & $\begin{array}{c}\text { Data used } \\
\text { year/No. of data }\end{array}$ & Remark & \\
\hline \multirow{6}{*}{ Bongdong } & $0.15 \leq \mathrm{h} \leq 0.31$ & $\mathrm{Q}=10.261 \times(\mathrm{h}-0.150)^{2.006}$ & \multirow{6}{*}{$\begin{array}{c}2006 / 2 \\
2008 / 32\end{array}$} & $\begin{array}{l}\text { Low stage extrapolation } \\
\text { estimation equation }\end{array}$ & \multirow{3}{*}{$\begin{array}{c}\text { 01/01 00:00 } \\
\sim / 07 / 0110: 20 \\
\text { After 09/25 19:10 }\end{array}$} \\
\hline & $0.31<\mathrm{h} \leq 0.40$ & $\mathrm{Q}=533.345 \times(\mathrm{h}-0.270)^{2.363}$ & & $\begin{array}{l}\text { Extrapolated when less } \\
\text { than or equal to } 0.32 \mathrm{~m}\end{array}$ & \\
\hline & $0.40<\mathrm{h} \leq 1.65$ & $\mathrm{Q}=80.847 \times(\mathrm{h}-0.182)^{1.933}$ & & & \\
\hline & $0.32 \leq \mathrm{h} \leq 0.56$ & $\mathrm{Q}=259.175 \times(\mathrm{h}-0.320)^{2.134}$ & & & \multirow[t]{2}{*}{$\begin{array}{l}\text { 07/01 10:30 } \\
\sim 09 / 2519: 00\end{array}$} \\
\hline & $0.56<\mathrm{h} \leq 1.65$ & $\mathrm{Q}=80.847 \times(\mathrm{h}-0.182)^{1.933}$ & & & \\
\hline & $1.65 \leq \mathrm{h} \leq 7.75$ & $\mathrm{Q}=57.255 \times(\mathrm{h}-0.050)^{2.313}$ & & $\begin{array}{l}\text { Extrapolated when greater } \\
\text { than or equal to } 2.36 \mathrm{~m}\end{array}$ & Entire period \\
\hline
\end{tabular}

and thus, the calculation of average concentration is important. The methods for calculating the average concentration of sediment include the arithmetic mean method, which simply calculates the arithmetic mean of the concentration at a survey line, and the flow-weighted mean method, in which discharge is weighted for the concentration at a survey line. The former is a method that can be applied when the concentration of sediment is constant at each survey line of a cross section, and the latter is a method that can be applied to a spot where the concentration of sediment is different at each survey line (i.e., natural river). The flow-weighted mean method is a method that can be applied when the sediment concentration of a survey line and the section discharge that can represent the survey line are measured. To analyze the characteristics and consistency of the suspended load for the discharge, a distribution diagram of the average concentration was drawn, as shown in Figure 3.

The calculated concentrations of suspended load were diverse, ranging from $4.0 \mathrm{mg} / \mathrm{L}$ to $1642.0 \mathrm{mg} / \mathrm{L}$. For the average concentration of sediment, the range of fluctuation was generally large, and the tendency was also distributed. In addition, different trends were observed depending on the rising-falling-stagnant parts. For this phenomenon, the sediment concentration did not constantly increase or decrease depending on the increase or decrease in the discharge; and the trend was different depending on the rising and falling parts. The characteristic of sediment that shows different trends for each event was observed, and it is thought to be a characteristic where during rainfall, the sediment concentration changes having temporal difference depending on the increase or decrease in the discharge. 


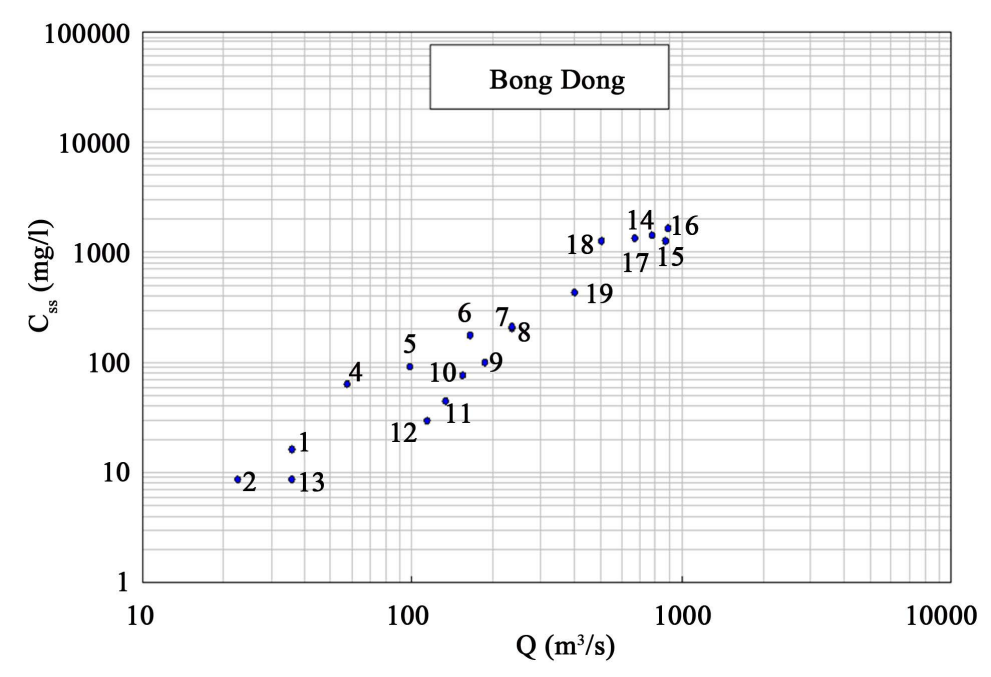

Figure 3. Discharge-suspended load concentration relation.

The BW pipe method, which has been selected to analyze the grain size distribution of the suspended load, is a method that is generally appropriate when concentration is low and a sample consists of mud or clay with a small particle size (Guy [3]). In the BW pipe method, for samples with a grain size of about $1.0 \mathrm{~mm}$, settling times of 1/6, 1/2, 1, 3, 7, 16, 40, 80, and 120 minutes are applied; and for samples with a grain size of about 1/16 $\mathrm{mm}$, settling times of $4,15,40,54,69,82,97,110$, and 124 minutes are applied. For the collected samples, the grain size distribution was analyzed by applying the settling times of 1/6, 1/2, 1, 3, 7, 16, 40, 80, and 120 minutes. The grain size distribution was examined by making the Oden Curve (percentage of residual suspended load for each sedimentation time) based on the results of the analysis (Table 2).

Total sediment load, which passes a section of a river, is calculated by adding the sediment loads of unmeasured section and measured section. However, a lot of time and effort are required to measure bed sediment load that is transported on the bed of a river. Especially, it is difficult to perform without the securement of measuring equipment and the expertise and abundant experience of a measure. Therefore, the bed sediment load was estimated by collecting bed material at each survey line during the measurement of suspended load. A sieve analysis method was used considering that the samples collected from the target spot were mostly coarse-grained. The sieve analysis was performed for the samples of each survey line. A grain size accumulation curve was drawn using the weight percent passing depending on the size of the sieve. Based on this, the bed characteristics of the target spot were examined. For the estimation of the total sediment load, representative factors that represent the characteristics of the target spot are used. Thus, the factors such as D35, D50, D65, D90, and $\sigma$ (gradation) were extracted by generating an average grain size accumulation curve. Also, the characteristics of cumulative grain size distribution were examined by calculating the coefficient of uniformity $\left(C_{g}\right)$ and the coefficient of curvature $\left(C_{g}\right)$, which are constants that represent the shape of a cumulative grain size distribution diagram. In general, if the coefficient of uniformity is large, it indicates an even distribution from small particles to large particles; and if the coefficient of uniformity is small, it indicates similar sizes of particles. Also, when the coefficient of uniformity is more than 10 , the particle size distribution is good; and when the coefficient of uniformity is less than 2, it indicates uniformity. However, for the coefficient of curvature, the particle size distribution is good when it is in the range of $1-3$.

The particle size distribution analysis of the bed material collected from the target spot was performed using the sieve analysis method, and Figure 4 shows the cumulative grain size distribution diagram depending on the results of the particle size distribution analysis. Table 3 summarizes the coefficient of uniformity and the coefficient of curvature. The coefficient of curvature was 0.97 , and the coefficient of uniformity was 1.80 . Therefore, the particle size distribution of the Bong-dong spot was found to be uniform and good.

\section{Development of a Discharge-Sediment Load Rating Curve}

A discharge-sediment load rating curve was developed by calculating the suspended sediment load and the total 
Table 2. Results of the suspended load analysis.

\begin{tabular}{|c|c|c|c|c|c|c|c|c|c|c|c|c|c|}
\hline \multirow{2}{*}{ No } & \multirow{2}{*}{$\begin{array}{l}\text { Survey } \\
\text { line }\end{array}$} & \multirow{2}{*}{$\begin{array}{l}\text { Concentration } \\
(\mathrm{mg} / \mathrm{L})\end{array}$} & \multicolumn{11}{|c|}{ Percentage of residual suspended load (\%) } \\
\hline & & & $0 \mathrm{~min}$ & $1 / 6 \min$ & $1 / 2 \min$ & $1 \mathrm{~min}$ & $3 \mathrm{~min}$ & $7 \mathrm{~min}$ & $16 \mathrm{~min}$ & $40 \mathrm{~min}$ & $80 \mathrm{~min}$ & $120 \mathrm{~min}$ & END \\
\hline \multirow{3}{*}{1} & 1 & 13.0 & 100.0 & 83.3 & 72.7 & 56.1 & 34.8 & 30.3 & 24.2 & 15.2 & 9.1 & 4.5 & 0.0 \\
\hline & 2 & 13.0 & 100.0 & 89.3 & 84.0 & 68.7 & 58.8 & 48.9 & 31.3 & 19.8 & 7.6 & 1.5 & 0.0 \\
\hline & 3 & 22.0 & 100.0 & 88.8 & 78.6 & 70.4 & 64.3 & 54.1 & 28.6 & 13.3 & 11.2 & 10.2 & 0.0 \\
\hline \multirow{3}{*}{2} & 1 & 15.0 & 100.0 & 91.3 & 80.4 & 71.7 & 60.9 & 50.0 & 38.0 & 23.9 & 20.7 & 6.5 & 0.0 \\
\hline & 2 & 4.0 & 100.0 & 94.0 & 88.0 & 80.0 & 66.0 & 54.0 & 34.0 & 28.0 & 22.0 & 8.0 & 0.0 \\
\hline & 3 & 7.0 & 100.0 & 95.1 & 78.0 & 63.4 & 56.1 & 43.9 & 34.1 & 31.7 & 24.4 & 9.8 & 0.0 \\
\hline \multirow{3}{*}{3} & 1 & 3.0 & 100.0 & 84.0 & 80.0 & 80.0 & 74.7 & 72.0 & 50.7 & 40.0 & 29.3 & 18.7 & 0.0 \\
\hline & 2 & 2.0 & 100.0 & 75.7 & 56.8 & 51.4 & 45.9 & 37.8 & 35.1 & 24.3 & 10.8 & 8.1 & 0.0 \\
\hline & 3 & 7.0 & 100.0 & 79.1 & 53.7 & 44.8 & 34.3 & 29.9 & 28.4 & 23.9 & 11.9 & 9.0 & 0.0 \\
\hline \multirow{3}{*}{4} & 1 & 55.0 & 100.0 & 85.5 & 75.0 & 66.9 & 58.1 & 49.2 & 34.7 & 21.4 & 11.3 & 2.4 & 0.0 \\
\hline & 2 & 98.0 & 100.0 & 85.0 & 73.6 & 62.8 & 51.0 & 40.2 & 27.5 & 14.4 & 8.7 & 4.0 & 0.0 \\
\hline & 3 & 38.0 & 100.0 & 84.7 & 79.7 & 68.9 & 59.5 & 48.6 & 32.4 & 20.3 & 11.3 & 6.8 & 0.0 \\
\hline \multirow{3}{*}{5} & 1 & 79.0 & 100.0 & 86.3 & 73.5 & 62.7 & 49.3 & 40.2 & 37.3 & 21.2 & 11.4 & 4.9 & 0.0 \\
\hline & 2 & 114.0 & 100.0 & 86.4 & 77.9 & 67.4 & 55.2 & 41.2 & 27.1 & 15.0 & 7.9 & 4.0 & 0.0 \\
\hline & 3 & 79.0 & 100.0 & 87.7 & 77.1 & 67.8 & 56.9 & 43.9 & 30.2 & 15.0 & 8.2 & 3.5 & 0.0 \\
\hline \multirow{3}{*}{6} & 1 & 3.0 & 100.0 & 84.0 & 80.0 & 80.0 & 74.7 & 72.0 & 50.7 & 40.0 & 29.3 & 18.7 & 0.0 \\
\hline & 2 & 2.0 & 100.0 & 75.7 & 56.8 & 51.4 & 45.9 & 37.8 & 35.1 & 24.3 & 10.8 & 8.1 & 0.0 \\
\hline & 5 & 7.0 & 100.0 & 79.1 & 53.7 & 44.8 & 34.3 & 29.9 & 28.4 & 23.9 & 11.9 & 9.0 & 0.0 \\
\hline \multirow{3}{*}{7} & 1 & 170.0 & 100.0 & 87.4 & 75.7 & 64.7 & 52.5 & 37.1 & 22.0 & 11.4 & 6.9 & 3.7 & 0.0 \\
\hline & 2 & 251.0 & 100.0 & 81.9 & 69.3 & 57.2 & 43.4 & 26.4 & 11.5 & 6.4 & 3.1 & 1.1 & 0.0 \\
\hline & 3 & 179.0 & 100.0 & 86.4 & 75.6 & 63.2 & 52.1 & 36.2 & 19.5 & 9.1 & 3.3 & 1.1 & 0.0 \\
\hline \multirow{3}{*}{8} & 1 & 159.0 & 100.0 & 83.6 & 71.8 & 60.8 & 47.9 & 33.4 & 20.4 & 8.7 & 1.1 & 0.1 & 0.0 \\
\hline & 2 & 247.0 & 100.0 & 83.2 & 72.5 & 61.9 & 52.0 & 39.0 & 20.1 & 8.1 & 4.2 & 1.8 & 0.0 \\
\hline & 3 & 221.0 & 100.0 & 86.1 & 74.7 & 63.8 & 50.3 & 35.2 & 18.9 & 9.6 & 5.2 & 2.2 & 0.0 \\
\hline \multirow{3}{*}{9} & 1 & 87.0 & 100.0 & 87.0 & 78.9 & 67.9 & 58.0 & 43.7 & 28.7 & 15.8 & 9.0 & 5.1 & 0.0 \\
\hline & 2 & 93.0 & 100.0 & 79.7 & 69.1 & 59.0 & 45.7 & 33.0 & 20.7 & 9.1 & 2.7 & 1.1 & 0.0 \\
\hline & 3 & 118.0 & 100.0 & 88.6 & 79.6 & 69.8 & 56.7 & 44.4 & 29.1 & 21.6 & 6.9 & 1.6 & 0.0 \\
\hline \multirow{3}{*}{10} & 1 & 71.0 & 100.0 & 89.7 & 76.8 & 65.7 & 52.7 & 38.6 & 25.4 & 13.0 & 5.4 & 2.2 & 0.0 \\
\hline & 2 & 78.0 & 100.0 & 91.0 & 78.4 & 68.1 & 56.6 & 43.4 & 32.4 & 18.8 & 10.3 & 5.9 & 0.0 \\
\hline & 3 & 81.0 & 100.0 & 89.9 & 80.7 & 72.0 & 48.0 & 37.2 & 23.0 & 13.6 & 7.5 & 3.7 & 0.0 \\
\hline
\end{tabular}




\section{Continued}

\begin{tabular}{|c|c|c|c|c|c|c|c|c|c|c|c|c|c|}
\hline & 1 & 25.0 & 100.0 & 89.8 & 81.6 & 69.4 & 57.8 & 45.6 & 32.7 & 21.1 & 10.2 & 3.4 & 0.0 \\
\hline \multirow[t]{3}{*}{11} & 2 & 24.0 & 100.0 & 84.4 & 74.0 & 63.6 & 54.8 & 48.0 & 31.6 & 17.6 & 10.8 & 6.4 & 0.0 \\
\hline & 3 & 57.0 & 100.0 & 86.1 & 74.5 & 63.3 & 53.7 & 41.3 & 27.4 & 15.1 & 7.3 & 2.3 & 0.0 \\
\hline & 1 & 33.0 & 100.0 & 91.0 & 80.2 & 70.6 & 55.9 & 48.6 & 34.5 & 24.9 & 9.0 & 4.5 & 0.0 \\
\hline \multirow[t]{3}{*}{12} & 2 & 40.0 & 100.0 & 89.9 & 80.9 & 65.8 & 53.8 & 41.7 & 25.6 & 10.1 & 9.0 & 5.0 & 0.0 \\
\hline & 3 & 15.0 & 100.0 & 91.3 & 80.8 & 67.3 & 55.8 & 44.2 & 30.8 & 16.3 & 3.8 & 1.0 & 0.0 \\
\hline & 1 & 10.0 & 100.0 & 88.6 & 78.6 & 64.3 & 51.4 & 44.3 & 35.7 & 31.4 & 22.9 & 10.0 & 0.0 \\
\hline \multirow[t]{3}{*}{13} & 2 & 6.0 & 100.0 & 92.5 & 88.1 & 71.6 & 52.2 & 37.3 & 31.3 & 16.4 & 9.0 & 3.0 & 0.0 \\
\hline & 3 & 10.0 & 100.0 & 76.3 & 60.5 & 52.6 & 44.7 & 42.1 & 39.5 & 18.4 & 10.5 & 5.3 & 0.0 \\
\hline & 1 & 1547.0 & 100.0 & 74.2 & 61.7 & 47.6 & 28.9 & 16.7 & 8.9 & 4.3 & 2.0 & 0.8 & 0.0 \\
\hline \multirow[t]{3}{*}{14} & 2 & 1454.0 & 100.0 & 75.9 & 62.2 & 49.3 & 33.4 & 20.7 & 11.6 & 5.2 & 2.4 & 0.7 & 0.0 \\
\hline & 3 & 1240.0 & 100.0 & 86.2 & 74.7 & 63.5 & 44.9 & 25.8 & 12.9 & 5.7 & 2.4 & 0.8 & 0.0 \\
\hline & 1 & 1293.0 & 100.0 & 83.2 & 71.8 & 57.2 & 36.1 & 20.5 & 11.0 & 5.2 & 2.3 & 1.1 & 0.0 \\
\hline \multirow[t]{3}{*}{15} & 2 & 1157.0 & 100.0 & 84.0 & 70.5 & 54.5 & 31.5 & 17.2 & 9.0 & 4.4 & 2.1 & 1.0 & 0.0 \\
\hline & 3 & 1376.0 & 100.0 & 78.7 & 66.5 & 53.3 & 33.3 & 19.0 & 9.9 & 4.4 & 1.9 & 0.6 & 0.0 \\
\hline & 1 & 1645.0 & 100.0 & 83.5 & 71.2 & 58.7 & 37.8 & 21.5 & 11.4 & 5.3 & 2.2 & 0.8 & 0.0 \\
\hline \multirow[t]{3}{*}{16} & 2 & 388.0 & 100.0 & 83.0 & 71.8 & 60.2 & 42.1 & 26.3 & 14.4 & 6.3 & 2.5 & 1.0 & 0.0 \\
\hline & 5 & 1729.0 & 100.0 & 74.3 & 59.8 & 45.8 & 27.7 & 16.4 & 8.9 & 4.1 & 1.8 & 0.6 & 0.0 \\
\hline & 1 & 1828.0 & 100.0 & 93.3 & 81.0 & 68.0 & 49.4 & 30.7 & 17.2 & 8.1 & 3.3 & 1.2 & 0.0 \\
\hline \multirow[t]{3}{*}{17} & 2 & 292.0 & 100.0 & 83.2 & 72.3 & 61.0 & 44.4 & 27.8 & 15.4 & 7.0 & 3.0 & 1.2 & 0.0 \\
\hline & 3 & 1877.0 & 100.0 & 83.8 & 71.9 & 59.1 & 38.8 & 22.5 & 12.5 & 6.4 & 3.4 & 1.7 & 0.0 \\
\hline & 1 & 1092.0 & 100.0 & 78.7 & 67.1 & 55.8 & 40.7 & 26.2 & 14.9 & 6.9 & 2.5 & 0.7 & 0.0 \\
\hline \multirow[t]{3}{*}{18} & 2 & 1507.0 & 100.0 & 82.8 & 73.1 & 61.5 & 44.8 & 27.2 & 14.5 & 6.6 & 2.6 & 0.9 & 0.0 \\
\hline & 3 & 1096.0 & 100.0 & 86.2 & 74.7 & 62.9 & 49.2 & 37.2 & 20.8 & 9.6 & 3.9 & 1.1 & 0.0 \\
\hline & 1 & 466.0 & 100.0 & 81.2 & 69.6 & 60.3 & 49.1 & 36.6 & 22.7 & 11.2 & 5.1 & 2.3 & 0.0 \\
\hline \multirow[t]{2}{*}{19} & 2 & 449.0 & 100.0 & 88.3 & 77.5 & 66.1 & 52.1 & 37.1 & 22.3 & 10.4 & 5.5 & 2.1 & 0.0 \\
\hline & 3 & 349.0 & 100.0 & 85.4 & 74.6 & 64.2 & 52.4 & 37.2 & 23.8 & 11.6 & 4.2 & 1.4 & 0.0 \\
\hline
\end{tabular}

Table 3. Bed material grade ratio.

\begin{tabular}{ccccccc}
\hline D35 $(\mathrm{mm})$ & $\mathrm{D} 50(\mathrm{~mm})$ & $\mathrm{D} 65(\mathrm{~mm})$ & $\mathrm{D} 90(\mathrm{~mm})$ & $\begin{array}{c}\text { Coefficient of } \\
\text { uniformity } \\
(\mathrm{Cu})\end{array}$ & $\begin{array}{c}\text { Coefficient } \\
\text { of curvature } \\
(\mathrm{Cg})\end{array}$ & $\begin{array}{c}\text { Grade } \\
\text { coefficient } \\
\mathrm{t}(\mathrm{Ggr})\end{array}$ \\
\hline C31.27 & 36.36 & 41.35 & 51.23 & 1.80 & 0.97 & $\begin{array}{c}\text { Analysis } \\
\text { method }\end{array}$ \\
\hline
\end{tabular}




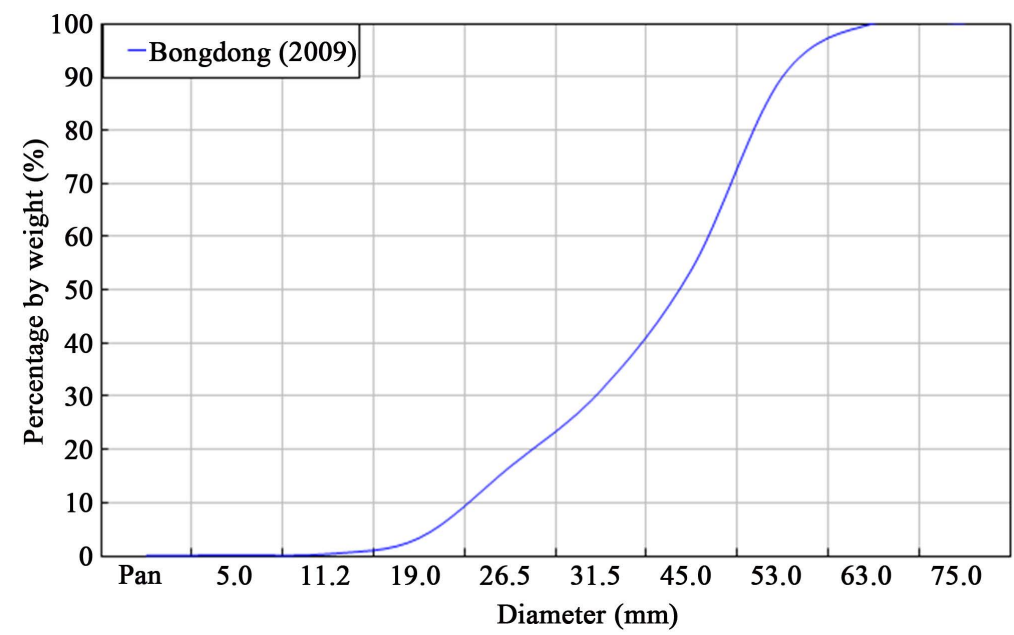

Figure 4. Bed material particle size distribution curve.

sediment load using the sediment load data and hydraulic data of the flood season that were obtained from the target spot. The suspended sediment load was calculated through multiplying the measured suspended load concentration by the discharge that corresponds to the stage at the time of the measurement. For the total sediment load, the discharge-total sediment load relation was estimated using the modified Einstein method (Colby and Hembree [4]), which can reflect the characteristics of measured suspended sediment load. However, the modified Einstein method also has a low reliability when applied to rivers other than alluvial rivers. Thus, careful caution and verification are required when this curve equation is used in practice. Therefore, the discharge-suspended sediment load rating curve developed based on the measurement results is significant as a curve equation that represents the relation between the discharge and the sediment load that occurred at the target spot.

The suspended sediment load was calculated using the suspended load concentration and the stage-discharge rating curve discharge. In general, for the calculation of suspended sediment load, measured discharge needs to be used rather than existing curve equation discharge. However, as discharge measurement could not be performed simultaneously with the sediment load measurement, the existing equation discharge was used. The applied stage-discharge rating curve has a representativeness since verification has been performed through longterm measurement. The total suspended sediment load was diverse (2.9 - $12674.8 \mathrm{t} / \mathrm{d})$; and for the maximum suspended sediment load, the maximum suspended sediment load was measured at a stage of $3.33 \mathrm{~m}(\mathrm{Q}=$ $893.34 \mathrm{~m}^{3} / \mathrm{s}$ ). Figure 5 shows the discharge-suspended sediment load relation. The degree of scattering is slightly large, but this shows the characteristics of the sediment that are divided by the rise and fall of the stage.

The sediment collection at the target spot was relatively evenly measured at the stage rising part and falling part that occurred depending on the rainfall event. Figure 6 shows the characteristics of the sediment where the suspended sediment load behaves in a loop shape depending on the stage rise and fall. To develop a dischargesediment load rating curve by reflecting these characteristics of the suspended load, it would be appropriate to develop a curve equation by dividing it into the rising part and the falling part.

Total sediment load is defined as the sum of suspended load, which is transported depending on the sediment supply ability of an upstream basin, and bed load, which occurs due to the water current intensity of a target channel. Total sediment load is also defined as the sum of wash load and bed material load depending on the relation with hydraulic variables, and as the sum of measured sediment and unmeasured sediment depending on a depth integration limit. In this regard, unmeasured section sediment load represents the sediment of the section in which a survey line has not been depth-integrated up to the entire water depth (i.e., unmeasured section).

In general, total sediment load is estimated using a direct method based on measurement or an indirect method based on the theoretical modeling of the behavior of sediment. The direct method, which estimates total sediment load by measuring suspended sediment load and bed sediment load at the same time, has the highest reliability. However, there are few cases of direct measurement because a lot of manpower and time are required to measure bed sediment load at a survey line. Therefore, the indirect method that theoretically models the behavior of sediment is widely used in Korea. However, the evaluation of which method is more appropriate can 


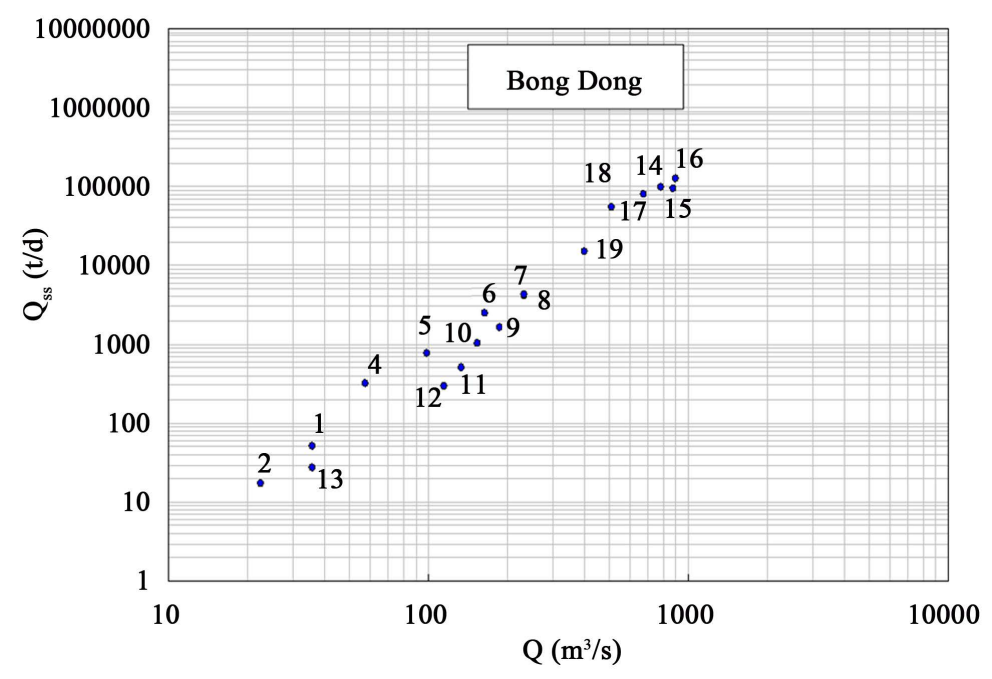

Figure 5. Discharge-suspended sediment load relation.



Figure 6. Comparison of the characteristics of the suspended sediment load for each event (July 12-July 14).

not be assured as of now because theories and methods for estimating total sediment load are different and the results are also significantly different depending on the characteristics of rivers.

The total sediment load was estimated using the indirect method, which theoretically models the behavior of sediment to draw a discharge-total sediment load relation. A method for estimating total sediment load that is appropriate for the characteristics of rivers in Korea has not yet been developed, and relevant research is also insufficient. Thus, among existing methods for estimating total sediment load, the modified Einstein method (Colby and Hembree [4]), which is relatively widely used in Korea, was selected, and was applied to the target spot. The modified Einstein method (Colby and Hembree [4]) was selected because this equation estimates total sediment load by reflecting measured suspended sediment load/hydraulic data and the characteristics of bed material. Figure 7 shows the results estimated using the modified Einstein equation. The model used in this study was developed by the Korea Institute of Construction Technology (Yu \& Woo [5]) in 1990. In the case of the estimated values using the above model, for the five measurement results (No. 5, No. 6, No. 10, No. 11, and No. 12), calculation was impossible or abnormally large sediment load was estimated. These abnormal results are thought to be characteristic of a gravel bed. 


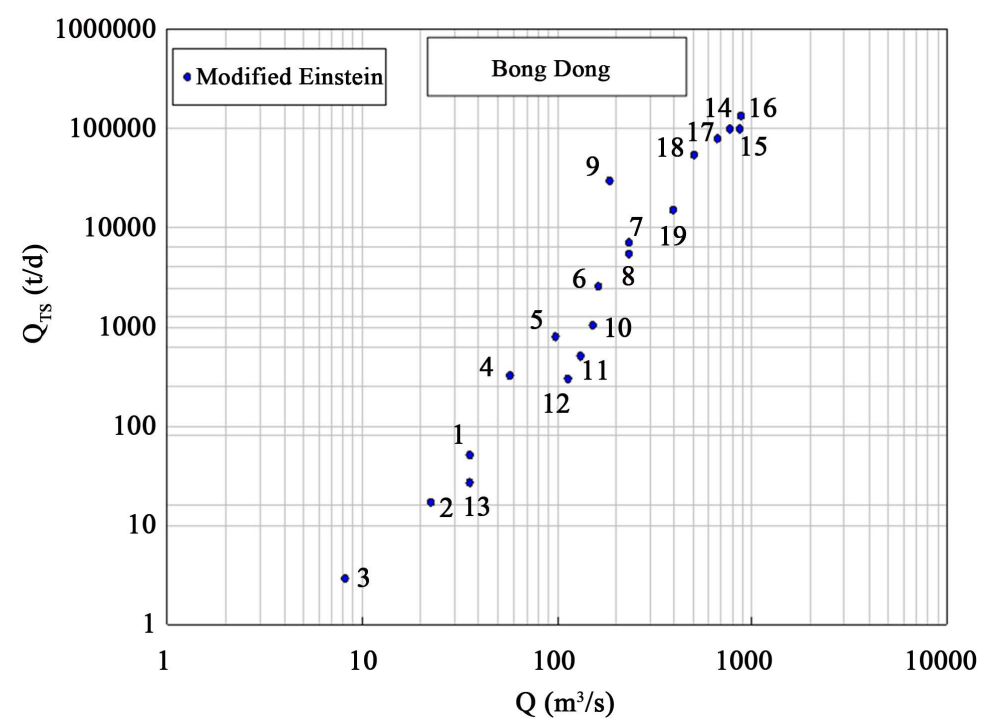

Figure 7. Results of the estimation of the total sediment load (Modified Einstein, [4]).

In this study, a discharge-suspended sediment load rating curve and a discharge-total sediment load rating curve were developed as shown in Equation (1) using the suspended load and hydraulic data measured at each survey line of the river section and the discharge data calculated from the stage-discharge rating curve developed in 2008.

$$
Q_{s s}=a Q^{b}
$$

where $Q_{s s}$ is the suspended sediment load (t/d), $a$ is the coefficient, $Q$ is the discharge $\left(\mathrm{m}^{3} / \mathrm{s}\right)$, and $b$ is the index that varies depending on the suspended load grain size and flow characteristics, and generally has a value of 1 - 3. In Figure 8, the relation between the discharge and the suspended sediment load was analysed for the development of a reliable discharge-suspended sediment load rating curve.

Methods for estimating total sediment load include an indirect method using river sediment load equations and a direct method based on measurement in the field. Also, existing sediment load equations estimate only bed material load; and when "wash load" is dominant, these sediment load equations cannot be used. Therefore, for reliable estimation of river sediment load, a method based on field measurement is mainly used.

In this study, bed load was not measured, and thus, a discharge-total sediment load rating curve was developed using the suspended load and bed material that had been directly measured in the field. The estimated total sediment load value used for the discharge-total sediment load rating curve was the value based on the modified Einstein method, and the results were shown in Figure 9.

\section{Conclusions}

The relation between discharge and sediment load that are discharged from the cross section of a river could assure its reliability when sediment concentration that corresponds to discharge is appropriately calculated. Accordingly, samples need to be collected using a method suitable for the characteristics of a target spot. Thus, in this study, sediment load measurement was planned through the multilateral examination of sediment load measurement cases and status in Korea, measurement methods, and ISO standard.

An ideal method for investigating the sediment load relation of a target spot is to collect the entire discharge that passes the entire cross section for a certain time. However, this method is theoretically possible, but is extremely unrealistic. Thus, it is difficult to be applied to actual rivers. Therefore, a method that divides the cross section of a river into several partial sections and collects sediment at the survey lines of these partial sections is widely used because it can be applied to actual rivers and is economical. This method calculates sediment load by collecting sediment at the survey lines of partial sections, and thus, substantial caution is required for the selection of the survey line arrangement of a cross section, number of survey lines, sampling methods, and measuring devices. 


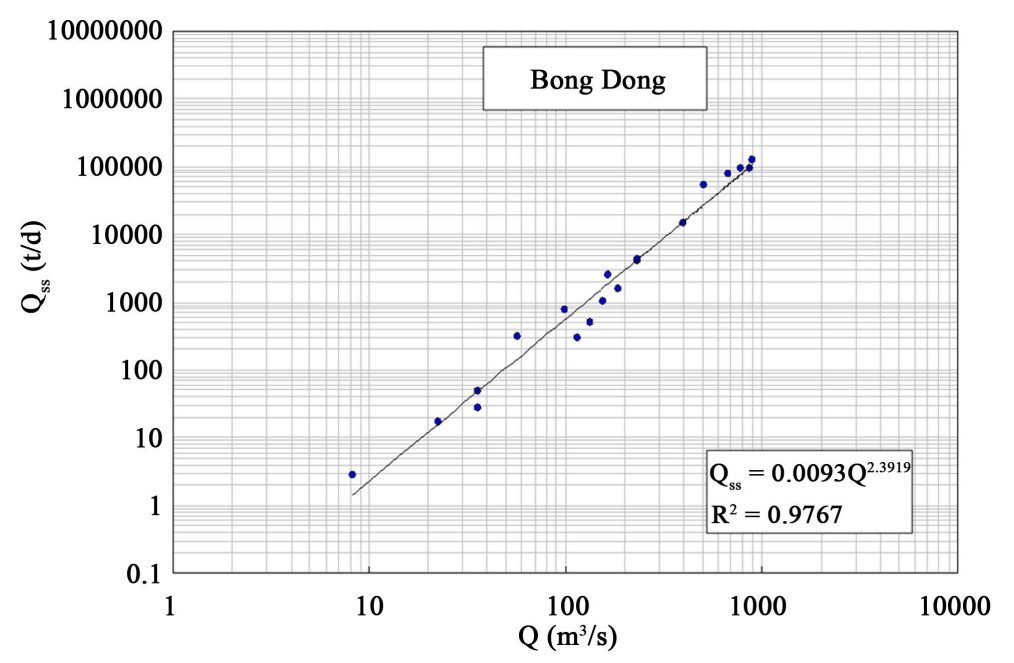

Figure 8. Discharge-suspended sediment load rating curve.

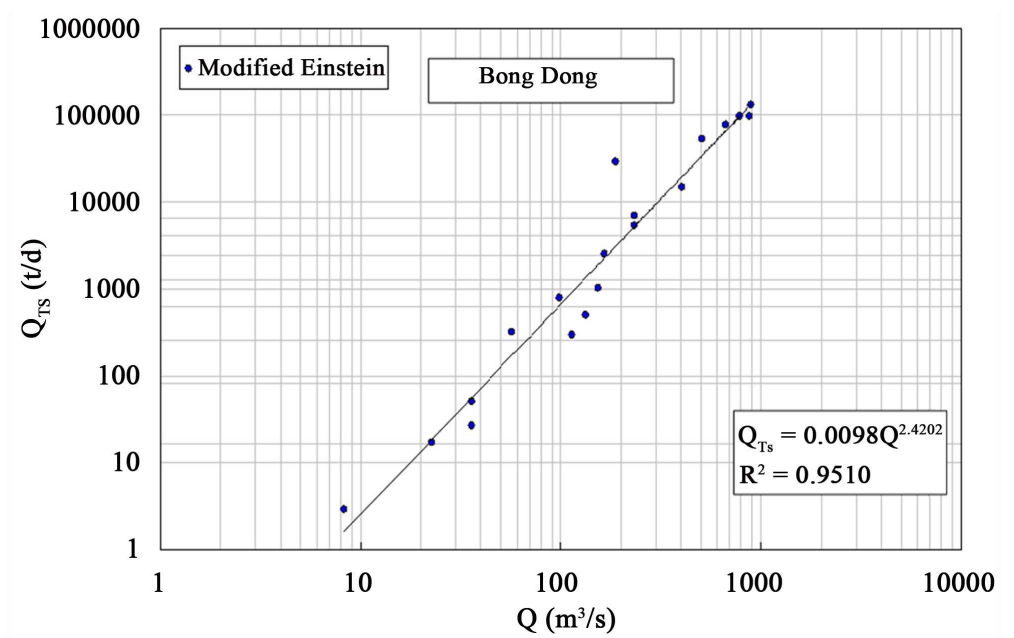

Figure 9. Discharge-total sediment load rating curve.

In the case of the standard for the number of survey lines, ISO suggests more than 5 - 7 survey lines depending on the water surface width of a channel; but in Korea, three survey lines are generally used. In this study, the plan was to follow the standard of ISO; but considering the field condition/practicality of the target spot and the channel characteristics/flowing water power in the flood season, three survey lines were collectively applied.

Sampling methods include a point integration method and a depth integration method, depending on the water depth of a survey line. In general, the point integration method is used when the water depth is deep and the vertical distribution of sediment is irregular, and the depth integration method is used when the water depth is less than about $5 \mathrm{~m}$. Therefore, the return water-depth integration method was used considering that the water depth at the Bong-dong spot was less than $5 \mathrm{~m}$. This is thought to be appropriate considering that the maximum water depth of the survey line at the Bong-dong spot in this year was $2.95 \mathrm{~m}$.

The characteristics of sediment change due to the basin, channel, and hydraulic data that change with time. Thus, to investigate the relation between discharge and sediment load that can represent a specific year, sediment load data that correspond to diverse discharge for each period are required. Also, the characteristics of sediment change depending on the outflow that occurs as the response of a basin due to rainfall, and thus, data that reflect these characteristics are also required. Therefore, to secure sediment load data that reflect these characteristics, sediment was collected at the rising part and falling part of the hydrograph where the increase or decrease in discharge occurs, and the sediment load measurement was performed at diverse discharge for each period. 
The sample analysis was performed using the filtration method, the BW pipe method, and the sieve analysis method. Through this, the concentration/grain size distribution of the suspended load and the grain size distribution of the bed material were examined.

A method for estimating total sediment load that is appropriate for the characteristics of rivers in Korea has not yet been developed. Thus, among existing equations for estimating total sediment load, the modified Einstein equation, which is relatively widely used in Korea, was applied. Using the calculated discharge and sediment load data, a discharge-sediment load relation considering the channel characteristics of the target spot was drawn. A method for estimating total sediment load that is appropriate for the characteristics of rivers in Korea has not yet been developed, and relevant research is also insufficient. Thus, among existing equations for estimating total sediment load, the modified Einstein equation, which is relatively widely used in Korea, was selected, and was applied to the target spot. The modified Einstein equation was selected because this equation estimates total sediment load by reflecting measured suspended sediment load/hydraulic data and the characteristics of bed material. The relation between discharge and sediment load that are discharged from the cross section of a river could assure its reliability when sediment concentration that corresponds to discharge is appropriately calculated. Accordingly, samples need to be collected using a method suitable for the characteristics of a target spot. Thus, in this study, sediment load measurement was planned through the multilateral examination of sediment load measurement cases and status in Korea, measurement methods, and ISO standard.

An ideal method for investigating the sediment load relation of a target spot is to collect the entire discharge that passes the entire cross section for a certain time. However, this method is theoretically possible, but is extremely unrealistic. Thus, it is difficult to be applied to actual rivers. Therefore, a method that divides the cross section of a river into several partial sections and collects sediment at the survey lines of these partial sections is widely used because it can be applied to actual rivers and is economical. This method calculates sediment load by collecting sediment at the survey lines of partial sections, and thus, substantial caution is required for the selection of the survey line arrangement of a cross section, number of survey lines, sampling methods, and measuring devices.

In the case of the standard for the number of survey lines, ISO suggests more than 5 - 7 survey lines depending on the water surface width of a channel; but in Korea, three survey lines are generally used. In this study, the plan was to follow the standard of ISO; but considering the field condition/practicality of the target spot and the channel characteristics/flowing water power in the flood season, three survey lines were collectively applied.

Sampling methods include a point integration method and a depth integration method, depending on the water depth of a survey line. In general, the point integration method is used when the water depth is deep and the vertical distribution of sediment is irregular, and the depth integration method is used when the water depth is less than about $5 \mathrm{~m}$. Therefore, the return water-depth integration method was used considering that the water depth at the Bong-dong spot was less than $5 \mathrm{~m}$. This is thought to be appropriate considering that the maximum water depth of the survey line at the Bong-dong spot in this year was $2.95 \mathrm{~m}$.

The characteristics of sediment change due to the basin, channel, and hydraulic data that change with time. Thus, to investigate the relation between discharge and sediment load that can represent a specific year, sediment load data that correspond to diverse discharge for each period are required. Also, the characteristics of sediment change depending on the outflow that occurs as the response of a basin due to rainfall, and thus, data that reflect these characteristics are also required. Therefore, to secure sediment load data that reflect these characteristics, sediment was collected at the rising part and falling part of the hydrograph where the increase or decrease in discharge occurs, and the sediment load measurement was performed at diverse discharge for each period.

The sample analysis was performed using the filtration method, the BW pipe method, and the sieve analysis method. Through this, the concentration/grain size distribution of the suspended load and the grain size distribution of the bed material were examined.

A method for estimating total sediment load that is appropriate for the characteristics of rivers in Korea has not yet been developed. Thus, among existing equations for estimating total sediment load, the modified Einstein equation, which is relatively widely used in Korea, was applied. Using the calculated discharge and sediment load data, a discharge-sediment load relation considering the channel characteristics of the target spot was drawn. A method for estimating total sediment load that is appropriate for the characteristics of rivers in Korea has not yet been developed, and relevant research is also insufficient. Thus, among existing equations for estimating total sediment load, the modified Einstein equation, which is relatively widely used in Korea, was selected, and was applied to the target spot. The modified Einstein equation was selected because this equation es- 
timates total sediment load by reflecting measured suspended sediment load/hydraulic data and the characteristics of bed material.

\section{Acknowledgements}

This research was supported by the Internal Research Project (2013) of the Korea Institute of Construction Technology.

\section{References}

[1] Ministry of Construction and Transportation (1993) Mangyeong River and the Dongjin River Improvement Basic Plan. I-ri Regional Construction and Management Administration, Iksan Si.

[2] Hydrological Survey Center (2008) 2008 Discharge Survey Report.

[3] Guy, H.P. (1969) Laboratory Theory and Methods for Sediment Analysis. Techniques of Water-Resources Investigations of the United States Geological Survey, Book 5, Chapter C1.

[4] Colby, B.R. and Hembree, C.H. (1955) Computations of Total Sediment Discharge Niobrara River near Cody, Nebraska. Water Supply Paper 1357, US Geological Survey.

[5] Yu, K.K. and Woo, H.S. (1990) Comparative Evaluation of Some Selected Sediment Transport Formulas. KSCE Journal of Korean Society of Civil Engineers, 10, 67-75. 